Divers@ Revista Eletrônica Interdisciplinar,

Matinhos, v. 14, n. 2, p. 80-91, jul./dez. 2021

ISSN 1983-8921

doi: http://dx.doi.org/10.5380/diver.v14i2.83072

\title{
LITERATURA E EDUCAÇÃO AMBIENTAL: UMA POSSIBILIDADE DE DIÁLOGO
}

\section{ENVIRONMENTAL EDUCATION AND LITERATURE: A POSSIBILITY OF DIALOGUE}

\author{
Gisele Paiva Lima ${ }^{1}$ \\ Fábio de Carvalho Messa \\ Kayan Gusmão ${ }^{3}$
}

\begin{abstract}
Resumo
O presente artigo tem por objetivo apresentar uma sequência didática envolvendo práticas de leitura literária e reflexão voltadas à Educação Ambiental Crítica. A ação descrita foi desenvolvida durante as aulas de Literatura, no nono ano do Ensino Fundamental, Município de Matinhos, Litoral do Paraná, a fim de verificar a possibilidade da utilização de textos literários como instrumento pedagógico voltado à Educação Ambiental numa abordagem crítica social, dessa forma observando como os estudantes percebem as relações interpessoais e político-sociais na obra O Voluntário, de Inglês de Sousa, escritor paraense pertencente à escola literária naturalista, características temporais e regionais, confrontando-as com suas impressões sobre como se refletem no cotidiano. As atividades envolveram cinco momentos distintos: inicialmente foi apresentada a obra para apreciação individual, em seguida foram orientadas ações que promovessem a oralidade, proporcionando a reflexão e o diálogo constantes. Recortes das expressões orais e das produções escritas são descritas e analisadas ao longo do texto, no intuito de verificar os repertórios pré-existentes dos alunos e investigar possíveis ressignificações. A prática consistiu em cinco momentos divididos em 6 aulas de 45 minutos cada, na seguinte ordem: leitura inicial do conto escolhido sem contextualização, seleção de trechos significativos para os alunos, roda de conversa, confecção de painel e produção textual.
\end{abstract}

Palavras-chave: relações sociais; práticas de leitura; crítica social; aprendizagem significativa.

\begin{abstract}
This article aims to present a didactic sequence involving literary reading practices and reflection aimed at Critical Environmental Education. The action described was developed during Literature classes, in
\end{abstract}

\footnotetext{
* Artigo Original: Recebido em 30/09/2021 - Aprovado em 11/11/2021.

${ }^{1}$ Licenciada em Letras Português, Inglês e Respectivas Literaturas, Mestranda no Programa de Pós-Graduação em Rede Nacional para o Ensino das Ciências Ambientais (PROFICIAMB), Setor Litoral, Universidade Federal do Paraná (UFPR Litoral), Matinhos/PR, Brasil. e-mail: giseplima@gmail.com ORCID: https://orcid.org/0000-0002-6383-426X (autor correspondente)

${ }^{2}$ Graduado em Comunicação Social - Jornalismo, Graduado em Educação Física e Licenciado em Letras, Mestre e Doutor em Literatura, Mestre em Educação Física. Professor do Curso de Licenciatura em Linguagem e Comunicação e do Curso de Licenciatura em Educação Física da UFPR Litoral, Matinhos/PR, Brasil. e-mail: fabiomessa@ufpr.br ORCID: https://orcid. org/0000-0003-4718-6319

${ }^{3}$ Licenciado em Letras Português, Inglês e Respectivas Literaturas, Professor da Educação Básica, Matinhos/PR, Brasil. e-mail: kayan.gusmao@escola.pr.gov.br ORCID: https://orcid.org/0000-0002-9298-1082
} 
the ninth year of Elementary School, Municipality of Matinhos, Coast of Paraná, in order to verify the possibility of using literary texts as a pedagogical tool aimed at Environmental Education in a critical social approach. way by observing how students perceive interpersonal and political-social relationships in the work O Voluntário, by Inglês de Sousa, a writer from Pará who belongs to the naturalist literary school, temporal and regional characteristics, confronting them with their impressions of how they reflect in daily life. The activities involved five different moments: initially, the work was presented for individual appreciation, then actions that promote orality were guided, providing constant reflection and dialogue. Snippets of oral expressions and written productions are described and analyzed throughout the text, in order to verify the students' pre-existing repertoires and investigate possible reinterpretations. The practice consisted of five moments divided into 6 classes of 45 minutes each, in the following order: initial reading of the chosen short story without contextualization, selection of significant excerpts for the students, conversation circle, panel making and textual production.

Keywords: social relationships; reading practices; social criticism; meaningful learning.

\section{Introdução}

Durante algum tempo, diversas correntes de Educação Ambiental (EA) foram voltadas a uma prática de conservação da Natureza como preservação de recursos ou manutenção territorial, colocando o ser humano em uma condição à parte desse conjunto, porém as mais atuais nos mostram a indissociabilidade entre relações humanas e o ambiente ressignificando ser humano como parte da Natureza e o cuidado com esta espécie como cuidado com a Natureza.

Dentro da perspectiva de trabalhar a Educação Ambiental como uma abordagem sobre as relações sociais e as interferências destas com o meio ambiente, questiona-se: É possível trabalhar Educação Ambiental utilizando textos literários como instrumento pedagógico? Como os estudantes das séries finais do Ensino Fundamental percebem as relações político-sociais e sua interferência na qualidade de vida?

Partindo de tais questionamentos, este material objetiva apresentar uma prática pedagógica realizada, durante aulas de literatura, baseada na leitura do texto naturalista $O$ Voluntário, de Inglês de Souza, seguindo a proposta de EA de Carvalho (2004) e Guimarães (2013) tratando-a como uma forma de ressignificar o cuidado com o outro e transformar a educação ambiental em uma educação política.

A prática consistiu em cinco momentos divididos em 6 aulas de 45 minutos cada, na seguinte ordem: leitura inicial do conto escolhido sem contextualização, seleção de trechos significativos para os alunos, roda de conversa, confecção de painel e produção textual.

\section{Revisão de literatura}

Objetivando tratar a Educação Ambiental como um processo permanente, superando a construção histórica ocidental antropocêntrica de que o ser humano é colocado como elemento separado da natureza e superior a ela (Porto-Gonçalves, 2010), as práticas aqui relatadas procuram refletir sobre as relações entre seres humanos e como os jovens as percebem.

Ao ressignificar o cuidado para com a natureza e para com o Outro humano como valores ético-políticos, a educação ambiental crítica afirma uma ética ambiental, balizadora das decisões sociais e reorientadora dos estilos de vida coletivos e individuais. Aqui, juntamente com uma educação, delineiam-se novas racionalidades, constituindo os laços identitários de uma cultura política ambiental. (CARVALHO, 2004, p. 19)

Já no início de sua obra Ensinar a Viver: Manifesto para mudar a educação, Edgar Morin (2015) apresenta uma visão sobre a utilidade do que se tenta ensinar nas escolas destacando o papel da Literatura. 
Certamente, ler, escrever, calcular são coisas necessárias ao viver. $\mathrm{O}$ ensino da Literatura, da história, das matemáticas, das ciências contribui para a inserção na vida social; o ensino da literatura é ainda mais útil pelo fato de desenvolver, ao mesmo tempo, a sensibilidade e o conhecimento; o ensino da filosofia estimula em cada mente receptiva a capacidade reflexiva e, seguramente, os ensinos especializados são necessários à vida profissional. (MORIN, 2015, p. 16).

Da mesma forma, a Literatura é colocada aqui como um elemento primordial para o desenvolvimento do trabalho em questão por trazer em si além do caráter subjetivo e reflexivo também uma vasta possibilidade de conteúdos das demais áreas do conhecimento "pois todas as ciências estão presentes no monumento literário" como pronunciou Barthes (2013). Nesta concepção, o texto literário assume o papel de um dos sujeitos do que é chamado por Barros (2007), com base em seus estudos sobre o Círculo de Bakhtin ${ }^{\mathrm{i}}$, como dialogismo interacional, sendo o leitor, seu interlocutor, o outro sujeito entendendo que cada um destes é caracterizado por pertencer a uma classe social e por ser construído histórica e ideologicamente.

Foi selecionado para o desenvolvimento do trabalho o conto $O$ Voluntário do escritor paraense Inglês de Sousa (1853-1918), presente na obra Contos Amazônicos.

A narrativa se passa na cidade de Alenquer, localizada na Província do Amazonas, durante o século XIX. Jovens estavam sendo recrutados contra sua vontade para lutar na Guerra do Paraguai, que ocorreu entre 1864 e 1870.

Nesta obra, Pedro, rapaz com uma personalidade digna dos heróis românticos por sua bondade e leveza no ser, contrastando com o que se espera usualmente do caboclo e sua "pele cor de cobre" e suas "feições achatadas e grosseiras"; leva uma vida simples junto de sua mãe, Rosa, com limitações no que diz respeito a conforto e posses materiais, porém dono de grande paz e afetividade.

O mesmo é retirado violentamente de sua casa como prisioneiro e obrigado a participar do que o autor chama de "a comédia do voluntariado". Apenas jovens do dito "povo miúdo" foram forçados à linha de frente de uma batalha a qual não pertenciam.

No decorrer do conto são abordadas explicitamente situações de hierarquização estabelecidas pelo considerado mais civilizado ou menos civilizado, a banalização da dor do outro e a desvalorização da integridade física e da vida dos menos favorecidos por uma classe que se julga dominante, mostrando o conflito de interesses privados e coletivos no cerne dos problemas socioambientais (ACSELRAD, 1993).

\section{Metodologia}

A pesquisa foi realizada durante as aulas de Literatura, as quais ocorrem uma vez por semana, como um componente curricular separado de Língua Portuguesa, com alunos, de idade entre 13 e 14 anos, matriculados no nono ano do Ensino Fundamental moradores da área urbana do município de Matinhos, litoral do Paraná.

Vale ressaltar que tal componente curricular foi construído ao longo da história da instituição de ensino como um projeto inicialmente integrado à Língua Portuguesa como atividade adicional, posteriormente sendo incluído no currículo como disciplina com carga horária própria. Tal processo iniciou-se 13 anos atrás, e há 10, Literatura é ministrada pela mesma professora, acompanhando as turmas do sexto ao nono ano, criando assim uma oportunidade de desenvolvimento de projetos pedagógicos mais duradouros e estabelecimento de diálogo mais próximo com os estudantes.

Marco Antônio Moreira (2010) apresenta a aprendizagem significativa como caracterizada "pela interação entre conhecimentos prévios e conhecimentos novos", de forma não literal e não arbitrária, assim, conhecimentos prévios podem ser ressignificados ou reforçados e novos conhecimentos passam a assumir significado; e esta depende principalmente de duas condições: a escolha do material a ser utilizado e a predisposição para aprender.

Partindo da leitura do conto $O$ Voluntário, foram desenvolvidas atividades a fim de analisar os repertórios dos estudantes e suscitar discussões despertando um olhar crítico sobre as relações sociais e ambientais, segundo o que é proposto por Alberto Alzate Patiño (1994), da Universidade de Córdoba (Colômbia), o qual compreende vários 
elementos da corrente de crítica social, apresentado por Lucie Sauvé (2005)

Cada texto é analisado em função de suas intenções, de seu enfoque, de seus fundamentos, das implicações destes últimos, de sua significação fundamental em relação ao meio ambiente. Do conjunto destes textos, se desprendem depois diferentes problemas: problemas de saber, de ação e de saber-ação. Passa-se assim da temática à problemática, através de diferentes discursos. A segunda etapa é relacionar a problemática explorada pelos textos com a realidade local, cotidiana (SAUVÉ, 2005, p.31)

A sequência de atividades foi dividida em cinco momentos obedecendo a uma ordem.

Com o objetivo de verificar as percepções iniciais dos estudantes e não contaminar seu processo de leitura não ocorreu contextualização prévia da obra ou autor, assim, não haveria o que procurar especificamente para corroborar uma ideia anteriormente apresentada, pois

Na realidade, cada leitor é, quando lê, o próprio leitor de si mesmo. A obra do escritor é somente uma espécie de instrumento de ótica que ele oferece ao leitor a fim de permitirlhe discernir aquilo que sem o livro talvez não tivesse visto em si mesmo. (MALLARMÉ, 1945, p. 378 apud COMPAGNON, 2012, p.142)

Após esta leitura inicial de forma livre, o passo seguinte consistiu em cada estudante destacar trechos mais significativos e, dentro destes trechos, as palavras ou expressões marcantes, as quais poderiam causar sensações boas, ruins ou apenas curiosas. E depois disso, justificar oralmente as escolhas. Seguido de uma roda de conversa objetivando promover mais momentos de reflexão e interação.

Verificados os pontos de interesse dos alunos dentro da obra, foi confeccionado um cartaz com exemplos de ações ou situações acerca de um tema escolhido pela turma, possibilitando comparar os trechos destacados inicialmente com os transcritos nesta etapa.

Como atividade final foi proposta uma produção textual na qual poderiam defender seu ponto de vista sobre um ou mais assuntos abordados no conto utilizado como texto base.

\section{Apresentação dos resultados}

\subsection{Primeiro momento: leitura inicial (1 aula)}

Partindo do entendimento de que "a leitura implica sociabilidade, ou melhor, leitura é um ato que só se realiza plenamente quando o leitor sabe compartilhar com outras pessoas, presentes ou ausentes, significações" (JOBIM E SOUZA; GAMBA JÚNIOR, 2007), optou-se por dispor períodos de aula tanto para a leitura quanto para a efetivação das ações posteriores, possibilitando interações entre os envolvidos.

Durante a leitura inicial do texto algumas palavras chamaram a atenção dos alunos como velha em "A velha tapuia Rosa já não podia cuidar da pequena lavoura", pois estão habituados ao uso de idosa em textos escritos, o que causou certo estranhamento, bem como o uso de outros adjetivos como desempenado, desapiedado e cabisbaixos; também o aparecimento de espécies da fauna aquática as quais certos alunos já conheciam e expuseram algumas informações oralmente aos demais, como pirarucu e peixe-boi. Outras, como canaranas e sopapo, foram rapidamente pesquisadas com uso dos dispositivos móveis dos próprios estudantes.

Ao longo do primeiro contato com o texto, 50\% dos alunos manifestaram a necessidade de realizar nova leitura para entendê-lo melhor, $30 \%$ expuseram dificuldade vocabular e $20 \%$ alegaram desconforto pela descrição de algumas cenas consideradas violentas.

\subsection{Segundo momento: trechos significativos (1 aula)}

No segundo momento, aula realizada na semana seguinte, os alunos leram os trechos do conto que consideraram significativos ou que precisassem discutir com os colegas a fim de entender melhor e destacaram as expressões que mais chamaram a atenção. 


\section{TRECHO 1}

"O caboclo não ri, sorri apenas; e a sua natureza contemplativa revela-se no olhar fixo e vago em que se leem os devaneios íntimos, nascidos da sujeição da inteligência ao mundo objetivo, e dele assoberbada. Os seus pensamentos não se manifestam em palavras por lhes faltar, a esses pobres tapuios, a expressão comunicativa, atrofiada pelo silêncio forçado da solidão."

As expressões destacadas no trecho 1, associadas aos comentários orais, demonstraram estranheza dos adolescentes sobre a ausência de sons presentes no ambiente urbano, os quais estão habituados como músicas altas, veículos trafegando, ruído excessivo.

Falar é comum e o estímulo ao desenvolvimento vocabular também devido aos espaços sociais em que estão inseridos. Assim, a princípio houve o questionamento sobre a expressão natureza contemplativa. Durante a discussão surgiram duas possibilidades: a palavra natureza e seu significado como algo que já estava pronto desde sua concepção ou ser uma característica imposta pela falta de oportunidades de expressão oral, obrigando o caboclo a recolher-se à intimidade de seus pensamentos assim limitados a seus "devaneios íntimos".

Ao destacar "atrofiada pelo silêncio forçado da solidão", atrofiada foi diretamente ligada à falta de exercício da fala, fazendo com que o indivíduo torne-se introspectivo. Contudo a fala, neste caso, foi associada a uma necessidade exterior ao local de moradia do caboclo modificando o significado préconcebido de solidão neste contexto, visto que para eles seria um estado coletivo de solidão, evidenciando uma diferença cultural.
Para Morin (2011),

A cultura é constituída pelo conjunto dos saberes, dos fazeres, das regras, das normas, das proibições das estratégias, das crenças, das ideias, dos valores, dos mitos, que se transmite de geração em geração, se reproduz em cada indivíduo, controla a existência da sociedade e mantém a complexidade psicológica e social. Não há sociedade humana, arcaica ou moderna, desprovida de cultura, mas cada cultura é singular. (MORIN, 2011, p. 50-51).

Dentro de uma comunidade, como a apresentada no conto, os caboclos tinham seus afazeres e suas rotinas, conseguindo estabelecer a comunicação necessária entre si. Assim, o "silêncio forçado pela solidão" seria um distanciamento entre a comunidade de Pedro, mais vulnerável, e a cidade, menos vulnerável e considerada mais civilizada.

TRECHO 2

"Dessa melancolia contínua dão mostra principalmente as mulheres, por causa da vida que levam. Os homens sempre andam, veem uma ou outra vez gente e coisas novas. As mulheres passam toda a vida no sítio, no mais completo isolamento."

'Melancolia', para os alunos, assumia um significado, anterior à leitura, de algo momentâneo dentro das representações criadas por eles a partir de músicas, seriados televisivos, redes sociais, enfim de uma influência midiática que fez com que criassem imagens estereotipadas, relacionando-a a roupas, maquiagens e a um estilo de consumo, partindo neste momento para uma reflexão mais profunda sobre o assunto, abordado novamente no terceiro momento: roda de conversa. 


\section{TRECHO 3}

“Ninguém o podia dizer, mas é certo que até o princípio do ano de 1865 correram tranquilos os dias no cacaual da velha Rosa. Quem não sabe o efeito produzido à beira do rio pela notícia da declaração da guerra entre o Brasil e o Paraguai? Nas classes mais favorecidas da fortuna, nas cidades principalmente, o entusiasmo foi grande e duradouro. Mas entre o povo miúdo o medo do recrutamento para voluntário da Pátria foi tão intenso que muitos tapuios se meteram pelas matas e pelas cabeceiras dos rios, e ali viveram como animais bravios sujeitos a toda a espécie de privações. Falava-se de Francisco Solano López nos sertões do interior da província como dum monstro devorador de carne humana, dum tigre incapaz de um sentimento humanitário."

A opção do autor pelo adjetivo 'velha' foi considerada desagradável e desrespeitosa, dada a orientação constante da preferência por 'idosa'. Durante esta observação podemos nos pegar pensando sobre a necessidade de explicar as características das escolas literárias e o contexto de produção da obra, porém, tal atitude influenciaria a continuidade da pesquisa.

Embora neste mesmo parágrafo seja apresentado o ano em que a narrativa ocorreu, a palavra 'guerra' despertou a atenção dos alunos para a época de fato, transportando-os para outro momento e criando novas possibilidades para a leitura do que vem a seguir no conto.

Mais uma vez voltou-se a discussão ao já abordado durante o trecho 1 sobre o distanciamento existente entre as pessoas de acordo com os grupos aos quais pertencem, afirmando-se nas expressões "classes mais favorecidas da fortuna", referindo-se aos que se encontravam em posições consideradas privilegiadas em oposição aos tapuios, neste momento em condição de "animais bravios sujeitos a toda a espécie de privações". Além da distinção estabelecida entre grupos determinados de pessoas, que já proporcionava a alguns mais conforto que a outros, foi acrescentada a atmosfera de medo fazendo aflorar o instinto de sobrevivência.

Nesse contexto, a figura de Francisco Solano López foi inserida acompanhada da expressão "monstro devorador de carne humana" inicialmente interpretada pelos alunos como sendo este um canibal.

TRECHO 4

“- Ora deixe-se de tolices. . Afinal que é que tem ser soldado? É até muito bonito, e as mulheres pelamse pela farda azul-ferrete e pelos botões amarelos. Não será uma honra para a tapuia velha o ter um filho oficial? Pois é o que pode muito bem acontecer, se você tiver juízo, não beber, não furtar, não fizer nenhuma má-criação, e resolver-se a aprender a leitura e a escrita, que não é lá bicho de sete cabeças. É verdade que você pode ficar prisioneiro dos paraguaios e mesmo morrer duma bala na cabeça, mas isso. . . São fatalidades. Também se morre na cama e até pescando pirarucus e caçando papagaios. Por isso deixe-se de asneiras, carinha alegre e marche-marche para o sul. Mesmo porque você está recrutadinho da silva e o que não tem remédio remediado está."

As expressões destacadas no trecho 4 evidenciam, segundo os estudantes, o machismo da instituição militar quando do uso apelativo de uma atração feminina pelo símbolo imposto por uma farda como argumento; a falsa propaganda de ascensão social e escolha do título de oficial; e a diminuição da sensação de danos ao optar por menosprezar acontecimentos como a perda da vida classificando-os como 'fatalidades, a fim de gerar um convencimento naquele que julgam inocente e vulnerável. 


\section{TRECHO 5}

"Foi uma cena terrível que teve lugar então. A velha Rosa, desgrenhada, com os vestidos rotos, coberta de sangue, soltava bramidos de fera parida. Pedro estorcia-se em convulsões violentas, e os soldados não conseguiam arredá-lo da mãe. Fabrício, ordenando que levassem o preso, lançara ambas as mãos aos cabelos da velha e puxando por eles procurava conseguir que largasse as roupas do filho. Os guardas, impacientes e coléricos, desembainharam a baioneta, e começaram a espancar alternativamente a mãe e o filho, animados pela voz e pelo exemplo do sargento, ainda pálido do susto que sofrera."

A cena descrita no trecho 5 gerou um momento de silêncio e comoção na turma sendo pouco comentada, porém, visivelmente incômoda. As expressões orais resumiram-se em falas como "quanta brutalidade" e "pra que fazer isso?"

\section{TRECHO 6}

"Começou logo o embarque dos recrutas. Eram vinte rapazes tapuios os que a autoridade obrigava a representar a comédia do voluntariado. Vi-os sair da cadeia, entre duas filas de guardas nacionais, e encaminharem-se para o porto, seguidos dos parentes, dos amigos e de simples curiosos."

O tom irônico proposto pelo autor em utilizar a "comédia do voluntariado", rapidamente substituído pelos estudantes por a "tragédia do voluntariado" evidenciou uma interpretação mais ampla do texto, relacionando a gradação dos acontecimentos até culminar em tal expressão, tida por eles como uma forma de criticar dentro do conto o que poderia ser presenciado fora dele como forma de expressar o entendimento de que "sem liberdade para exercer a cidadania, as normas prescritas tornam-se meras categorias formais e nada significam.” (PILON, 2014)

TRECHO 7

"Iam cabisbaixos, uns corridos de vergonha, como criminosos obrigados a percorrer as ruas da cidade nas garras da justiça; outros resignados e imbecis como bois caminhando para o matadouro; outros ainda procurando encobrir sob uma jovialidade triste as amarguras íntimas; todos marchando maquinalmente, alheios ao que se passava e dizia em redor de si, e oferecendo um aspecto de apatia covarde e idiota. Vestiam calça e camisa de algodão riscado, a mesma roupa com que uma semana antes arpoavam pirarucus ou plantavam mandioca nas roças da beira do rio. Alguns, aqueles de quem se desconfiava, por mais valentes e ágeis, traziam algemas."

\subsection{Terceiro momento: roda de conversa (1 aula)}

Para iniciar a roda de conversa foi pedido que os alunos refletissem sobre o conto e o dividissem em dois momentos usando quaisquer critérios para classificá-los e, posteriormente, comentar suas respostas comparando-as às demais. Os 10 participantes identificaram o mesmo momento da narrativa, já citados anteriormente nos trechos $3 \mathrm{e}$ 4, como separação do que consideraram situação de tranquilidade/paz (descrição do ambiente e a vida simples da população) e passagem para o que chamaram de período perturbador (imposição do recrutamento) classificação utilizada por $60 \%$ dos envolvidos.

Mesmo observando um equilíbrio inicial, questões sobre os possíveis sentidos por eles atribuídos à palavra 'melancolia', ressignificando conhecimentos prévios (MOREIRA, 2010), como uma condição 
indicando continuidade de sensação e como esta afetava principalmente às mulheres das comunidades mais isoladas, foram discutidas novamente, evidenciando a discordância dos alunos a uma cultura segregadora. Convém informar que $40 \%$ da turma é composta por estudantes do gênero feminino e $60 \%$ do gênero masculino.

Por se tratar de um texto complexo e provocativo no que diz respeito à abordagem sobre as relações interpessoais, houve a necessidade de retomada da leitura a cada momento.

A distância existente entre nossa cidade e o local onde ocorre a narrativa gerou curiosidade e fez com que levantassem algumas hipóteses sobre o autor e suas intenções. Uma estudante revelou ter sentido dúvida sobre a simpatia do autor em relação aos caboclos, pois considerou algumas descrições pejorativas.

No decorrer da ação, a participação mais efetiva foi em relação ao exposto no trecho 5. A leitura do trecho foi comentada por $90 \%$ dos alunos, em comparação ao exposto durante o primeiro momento. Sobre a sensação de incômodo causada pela descrição das cenas de violência física, passaram de $20 \%$ dos alunos para os $90 \%$ que se dispuseram a comentar o trecho.

\subsection{Quarto momento: painel colaborativo (1 aula)}

A partir das discussões realizadas na semana anterior, ficou evidente a percepção dos estudantes em relação às situações de manifestação do que julgavam como violência ou agressividade. Assim, foi proposto que cada um transcrevesse 1 ou 2 exemplos dentro da obra com uma breve justificativa para compor um painel/cartaz em conjunto, proporcionando registro e novas oportunidades de reflexão sobre seus pontos de vista, pois o mesmo permaneceu exposto em sala de aula e disponível a alterações.

Ao expressarem oralmente os estudantes classificaram espontaneamente os trechos recortados como: violência contra o ser humano (agressões físicas e banalização do sofrimento alheio como no momento do recrutamento de Pedro); contra a natureza (invasão da comunidade gerando desequilíbrio no ambiente e entorno); contra espaços culturais (desrespeito ao modo de vida dos ribeirinhos, forçando-os a trocar uma realidade isolada e a vida da pesca pela guerra); contra leis (imposição do alistamento contra a vontade, desrespeito ao direito de representação legal); contra instituições (pública militar pelo uso simbólico da hierarquia como representação de poder; e familiar, por separar os recrutas de seu convívio), demonstrando a necessidade de dialogar sobre como a sociedade é estruturada com base nas relações de poder, possibilitando uma educação política a fim de gerar ação como sujeitos na história (GUIMARÃES, 2013).

Pelas escolhas, é perceptível que a cena mais marcante para a maioria dos estudantes foi a descrição do momento em que mãe e filho são brutalmente separados.

“[...] e atirou-se contra o tenente, procurando arrancar-lhe os olhos com as aguçadas unhas.”

"Morrer com uma bala na cabeça quando carregar o golpe foi agarrado o capitão"

"[...] Fabrício segurou-a por um braço e atirou-a de encontro a um esteio da casa... A velha Rosa desgrenhada com os vestidos rotos coberta de sangue, soltava bramidos de fera parida."

"Embora contra a vontade do libertando o libertasse a tiro." 
"Castigos corporais e maus tratos;

Agressões do exército e puxões de cabelo;

Agressão verbal."

"Lançara ambas as mãos aos cabelos da velha e puxando."

\subsection{Quinto momento: produção textual (2 aulas)}

A proposta de produção consistiu na escrita individual de um texto que deveria conter a opinião dos estudantes sobre os assuntos abordados no conto. Para tal, houve apresentação dos trechos mais comentados pelos alunos durante o processo de leitura e retomada das discussões anteriores, pois "todo enunciado emerge sempre e necessariamente num contexto cultural saturado de significados e valores e é sempre um ato responsivo, isto é, uma tomada de posição neste contexto.” (FARACO, 2009)

Todas as produções iniciaram com um breve resumo da obra e algumas situações da narrativa foram citadas de forma recorrente. A seguir estão expostos alguns trechos dos textos finais dos estudantes a fim de exemplificar algumas percepções e diferentes perspectivas.

\section{TEXTO 1}

"No conto encontramos muita violência presente como em 'falava-se de Francisco Solano Lopez nos sertões do interior da província como dum monstro devorador de carne humana'. Nessa parte do conto ele expressa o canibalismo, mas não é exatamente isso que ele quer dizer, ele quer dizer de um homem que matava muita gente e assim acredito que muitos ficavam aterrorizados com a presença dele, [...]”

L.N.L.

\section{TEXTO 2}

"Percebe-se que no decorrer do conto tivemos várias situações de violência como violência aos idosos e recrutas, causadas por pessoas superiores no caso do idoso ocorreu porque o agressor era mais forte, os recrutas foram agredidos pelo fato de que estavam no exército e alguns tinham cargo superior achando que podiam ser violentos com os outros."

M.H.A.C.

\section{TEXTO 3}

"Observamos que o povo tinha medo de ir para a guerra, ou serem mortos e pegos pelos paraguaios, por isso eles se escondiam no mato e nas cabeceiras dos rios: medo da guerra, dos paraguaios e dos generais.” 


\section{TEXTO 4}

“A desigualdade de gênero na obra lida já é uma representação básica do que acontecia nesta época, por exemplo, as mulheres ficavam em casa presas enquanto os homens podiam sair, como se elas fossem propriedade particular dos maridos. Essas coisas já mudaram muito, mas infelizmente ainda não acabou.”

A.A.C.P

\section{TEXTO 5}

"Na minha opinião, o conto é um complô perfeito de como uma realidade pode ser moldada de acordo com como o leitor e o personagem se sentem sobre determinados assuntos, pois o texto não muda, mas sim a interpretação do leitor sobre o mesmo.”

Quando apresentados os trechos mais significativos, segundo momento, ainda pensavam na figura de um canibal como se a expressão "devorador de carne humana" assumisse apenas um sentido denotativo, limitando outras possíveis leituras.

Ao longo das atividades propostas, outros sentidos foram atribuídos como pode ser observado no texto 1 , pois a aluna modificou sua interpretação inicial interagindo com as informações com mais complexidade, inferindo um tom crítico em relação à imagem antecipada ou criada acerca de certas personalidades a fim de gerar uma atmosfera de medo.

Bem como consta no texto 2, uma enumeração de tipos de violência presentes no conto e exemplificadas nos momentos de exercício da oralidade. É possível notar a expressão de um controle proporcionado por imposição física ou de status dado por certa superioridade, distinguindo os indivíduos entre mais vulneráveis e mais fortes.

Tais desigualdade e medo também estão representados no texto 3 pelo estudante que expõe o fato de o povo ter que se esconder para fugir do recrutamento, listando alguns dos elementos geradores de temor, dentre eles, os generais. Ao passo que no texto 4, a questão desigualdade é retratada levando em conta as relações de gênero associadas à época da narrativa e à atualidade, discussão também bastante evidenciada durante os debates anteriores, situando as mulheres como detentoras de menos direitos que os homens.

A percepção, demonstrada pelo recorte do texto 5 , nos traz uma interpretação de um ponto de vista literário, pensando em como o leitor interage com o texto de acordo com sua época e seu repertório. Ao afirmar "o texto não muda, mas sim a interpretação do leitor sobre o mesmo", associando anteriormente a uma realidade que pode ser moldada de acordo com os sentimentos do leitor e personagens, o aluno se coloca em uma posição de coautor de uma nova narrativa, ou seja, de um texto que nunca será o mesmo, pois depende diretamente da relação existente entre seus interlocutores e de seus valores historicamente construídos (FARACO, 2009).

Os recortes textuais dados como exemplo podem nos mostrar algumas concepções coincidentes com o pensamento de Morin (2011) sobre a relação entre indivíduo, sociedade e espécie, entendendo uma obrigatoriedade de interdependência entre os três, pois um inexiste sem o outro.

Neste caso, os estudantes deixaram transparecer que para eles, provavelmente, os indivíduos, tanto caboclos quanto moradores da área urbana pertencentes a estas sociedades, deveriam reconhecer-se enquanto seres da mesma espécie, respeitando-se mutuamente, elencando em suas produções questões como vulnerabilidade física e social (textos 1, 2 e 3), diferença de gênero (texto 4) e relacionando-as à própria realidade como no texto 4 .

\section{Considerações finais}

Diante dos dados obtidos a partir deste estudo, verificou-se a viabilidade do uso de textos literários como valioso instrumento pedagógico para práticas 
de Educação Ambiental. Foram consideradas as possibilidades de leitura e diálogo, embora houvesse necessidade de tempo prolongado para apreciação e reflexão, sendo que inicialmente os estudantes mostraram-se receosos ao texto dada a dificuldade vocabular.

A opção por um texto naturalista, com vocabulário peculiar, regional, ambientado em outro estado e época, suscitou várias indagações levando ao questionamento, em alguns momentos, se a experiência seria promissora, pois tanto os estudantes poderiam aderir ao processo de leitura e socializar suas experiências, quanto calar e negar sua participação, frustrando a ação. Faz-se necessário apontar que esta postura por parte deles seria respeitada.

Mesmo demonstrando certa rejeição inicial, as situações descritas no conto geraram muitas sensações nos leitores, levando-os a responder ativamente, ao passo que suas trocas por meio de comentários orais ocorreram de forma majoritariamente espontânea.

Os alunos demonstraram seu ponto de vista sobre as relações político-sociais abordadas na obra, suas impressões acerca destas e como influenciavam a vida dos indivíduos presentes na narrativa transferindo a discussão para a realidade vivida por eles.

Nesse sentido, o fato desta turma ser acompanhada do sexto ao nono ano pela mesma professora, certamente, interferiu no desenvolvimento das atividades pela relação de diálogo e interação comuns aos envolvidos.

Vale considerar que, apenas a produção final como fonte de análise dos resultados, não refletiria integralmente a riqueza das discussões orais, embora tenha contemplado alguns aspectos não citados anteriormente.

\section{Referências}

ACSELRAD, H. Ecologia: direito do cidadão. Rio de Janeiro: Gráfica JB, 1993.

AlZATE PATIÑO, A.; CASTILlO, L.A.; GARAVITO, B.A.; MUÑOZ, P. Propuesta pedagógica para el desarrollo local ambiental. Una estrategia en construcción. Colombia: Planeta Rica, 1994.

BARTHES, Roland. Aula. São Paulo: Editora Cultrix, 2013.
CARVALHO, Isabel Cristina de Moura. Educação Ambiental Crítica: nomes e endereçamentos da educação. In: LAYRARGUES, Philippe Pomier. Identidades da educação ambiental brasileira. Brasília: Ministério do Meio Ambiente, 2004.

COMPagnon, Antoine. O Demônio da Teoria: Literatura e Senso Comum. Belo Horizonte: Editora UFMG, 2012.

FARACO, Carlos Alberto. Linguagem e Diálogo: As ideias linguísticas do Círculo de Bakhtin. São Paulo: Parábola Editorial, 2009.

GUIMARÃES, M. Por uma educação ambiental crítica na sociedade atual. Revista Margens Interdisciplinar, Abaetetuba, v. 7, n. 9, p. 11-22, set. 2013.

MOREIRA, Marco Antonio. O que é afinal Aprendizagem Significativa?. 2010. Disponível em: http://moreira.if.ufrgs.br/oqueeafinal.pdf . Acesso em 23 set. 2021.

MORIN, Edgar. Ensinar a viver: Manifesto para mudar a educação. Porto Alegre: Editora Sulina, 2015.

MORIN, Edgar. Os sete saberes necessários à educação do futuro. São Paulo: Editora Cortez, 2011.

PILON, André Francisco. A ocupação existencial do mundo: uma proposta ecossistêmica. In: PHILIPPI JR, Arlindo; PELICIONI, Maria Cecília Focesi. Educação ambiental e sustentabilidade. 2. ed ver. e atual. Barueri, SP: Manoele,2014.

PORTO-GONÇALVES, C. W. De saberes e de territórios: diversidade e emancipação a partir da experiência Latino-Americano. GEOgraphia, v. 8, n. 16, 4 fev. 2010.

SAUVÉ, L. 2005. Uma cartografia das Correntes em educação ambiental. In: M. SATO; I. C. M. CARVALHO (org.). Educação Ambiental. Porto Alegre: Artmed. P. 17-45.

JOBIM E SOUZA, S.; GAMBA JÚNIOR, N. Novos suportes, antigos temores: tecnologia e confronto de gerações nas práticas de leitura e escrita. Revista Brasileira de Educação, n. 21, p. 104-114, 2002. 
${ }^{\text {i } D e ~ a c o r d o ~ c o m ~ C a r l o s ~ A l b e r t o ~ F a r a c o ~(2009), ~ o ~ C i ́ r c u l o ~ d e ~}$ Bakhtin era um grupo multidisciplinar, ou seja, composto por pessoas com formação acadêmica e atuação profissional diversas, dentre os quais faziam parte Mikhail M. Bakhtin, Valentin N. Voloshinov e Pavel N. Medvedev. 